\title{
Cultivo de células de Schwann, un modelo del microambiente del sistema nervioso
}

\author{
Vilma C. Muñetón, Zayra V. Garavito, Hernán Hurtado
}

\begin{abstract}
Resumen
Algunos aspectos de la fisiopatología del sistema nervioso periférico pueden ser ampliamente estudiados en un modelo celular in vitro, enriquecido en células de Schwann. La célula de Schwann como glía del sistema nervioso periférico produce la mielina responsable de la transmisión saltatoria del impulso, influye en la actividad neuronal y da soporte y protección axonal. A su vez es blanco de procesos que alteran la normalidad del sistema nervioso periférico como neuropatías congénitas y/o desmielinizantes, lesiones nerviosas, respuesta a patógenos neurotrópicos, etc., eventos más frecuentes y discapacitantes en individuos adultos. De ahí la importancia de obtener células a partir de animales adultos. Sin embargo, estas células son mitóticamente "lentas" y su obtención en cultivo requiere de condiciones específicas que estimulen su proliferación y actividad. Describimos a continuación, un modelo in vitro mediante el cual se obtienen cultivos enriquecidos en células de Schwann de ratón adulto, las cuales conservan características de las células in vivo, lo cual permite estudiar diversos fenómenos específicos del sistema nervioso periférico.
\end{abstract}

\section{Schwann cell cultures: a model of the nervous system microenvironment}

Some of the peripheral nervous system (PNS) physiopathological aspects can be studied in an in vitro cellular model of Schwann Cells (SC). SC as PNS glia produces myelin. Myelination increases the rate of impulse conduction. SCs influence neuronal activity and axonal support and protection. Also, they are the target of the process which alters the PNS, such as congenital and/or demyelinating neuropathies, nervous lesions, response to neurotrophic pathogens, etc., being the events most frequently found in adults. It is then important to obtain cells from adult animals. However, these cells are mytotically "slow" and growing them in culture needs specific conditions which stimulate proliferation and activity. An in vitro model to obtain highly enriched adult mouse SC cultures which have some of the in vivo SC cell cultures' features, is described. This method can be used to study several aspects of the nervous system biology. 
Las células de Schwann (CS) se derivan de la cresta neural y forman la glía del sistema nervioso periférico $(1,2)$. Sus funciones principales son, entre otras, la protección y el soporte metabólico axonal. Forman la envoltura de mielina, responsable de la transmisión saltatoria del impulso nervioso, dan sostén mecánico, aislan las prolongaciones neuronales entre sí e influyen en la regulación de su actividad, además de captar y almacenar sustancias neurotrasmisoras. Estas células contribuyen a los procesos de regeneración axonal en caso de lesiones, sirven de soporte físico y metabólico produciendo factores de crecimiento y moléculas de adhesión, entre otros (3-5), eliminan restos neuronales por fagocitosis, forman tejido cicatrizal e intervienen en la inmunidad local como presentadoras de antígenos exógenos en respuesta a patógenos (6).

Debido a la versatilidad e interés en sus funciones, estas células han sido blanco de diferentes estudios durante los últimos años y han sido sometidas a diversos procedimientos con el fin de obtener cultivos de células altamente enriquecidos. Existen varias fuentes de células de Schwann para cultivos: los nervios perifériccs y los ganglios de la raíz dorsai (DRG) que poseen no sólo fibras nerviosas sino que agrupan cuerpos neuronales de neuronas sensoriales (7). Adicionalmente, son utilizadas líneas celulares como la RN222, la 33B y la RT4-DGP2T obtenidas a partir de schwannomas (8), o la TSC a partir de células transfectadas con plásmidos (9).

La proliferación de las células de Schwann sólo ocurre naturalmente durante el desarrollo o después de una lesión nerviosa. En el momento del nacimiento, más del $70 \%$ de las CS han detenido su división en nervios ciáticos de roedores $\mathrm{y}$, en los adultos, la proporción de células que se dividen es menor de $1 \%(10)$, in vitro, a diferencia de otros tipos celulares -como los fibroblastos- las CS proliferan muy lentamente en medios convencionales que contengan suero. Los estudios han mostrado que el uso de mitógenos es útil en la inducción de la proliferación de estas células (11). Es así como se han ensayado diversos agentes mitogénicos en estudios in vitro y se ha observado que las células de Schwann responden a diferentes agentes, como la toxina colérica o la forscolina, que elevan el cAMP intracelular $(9,10,12,13,14)$ a elementos de la matriz extracelular, como la fibronectina (15) y el colágeno (16), a factores de crecimiento como el factor de crecimiento glial (17), el factor de crecimiento fibroblástico $\alpha$ y $\beta$ (18), el factor de crecimiento transformante $\beta(19,20)$, el factor de crecimiento derivado de plaquetas, el factor de crecimiento epidérmico (18) y por factores solubles en el sobrenadante de segmentos nerviosos (21). La proliferación celular también es estimulada por el contacto axonal por mecanismos aún desconocidos $(3,22,23)$. A este nivel, las heregulinas y Gas6 (17) como componentes mitogénicos axonales inducen proliferación a través de receptores tirosinacinasa sobre las células de Schwann (24). A su vez, responden a otros elementos presentes en el suero como el plasminógeno (25).

El efecto mitogénico de estas sustancias depende también de la edad de los individuos donantes, sean embriones, recién nacidos o adultos. Así, debido a la alta tasa mitótica en ei ciesarro!'o, es más eficiente la recuperación in vitro de CS a partir de embriones y recién nacidos. Debido a esto, la mayoría de los estudios funcionales de CS se han realizado con células procedentes de dichos animales. Sin embargo, recientes investigaciones han indicado que las CS cambian sus propiedades fisiológicas con la edad. EI RNAm de la GFAP es expresado sólo en ratas adultas después de los diez días de nacidas. Se detectan receptores al NGF en células inmaduras pero poco encontrados en células completamente desarrolladas (16). La expresión de moléculas del complejo mayor de histocompatibilidad presentadoras de antígeno puede ser diferencialmente inducidas por el interferón ã en células adultas y embrionarias (6). También la expresión de moléculas de la mielina como enzima característica 2, 3, nucleótido cíclico 3 fosfohidrolasa son moduladas por el desarrollo (26). La importancia en neuropatología de 
estudiar el papel real de las células de Schwann adultas en reparación, regeneración poslesión, rechazo a injertos (27), enfermedades desmielinizantes, neuropatías congénitas y respuesta a patógenos, entre otros, es evidente.

Obedeciendo a la necesidad de contar con un modelo in vitro de cultivo de células de Schwann adultas, describimos a continuación un método que permite la obtención de cultivos enriquecidos, en el cual, las células conservan características de la célula de Schwann in vivo, simulando el microambiente neural.

\section{Materiales y métodos}

\section{Cultivo de células}

Se ensayaron dos fuentes de células: nervio ciático y ganglio de la raíz dorsal (DRG) de ratones adultos (8-10 semanas) con $30 \mathrm{~g}$ de peso, aproximadamente, cepa ICR provenientes del bioterio de experimentación del INS. A su vez, los tejidos fueron ensayados en explantes o digeridos. Se usaron los explantes, basados en el hecho de que la mielina degradada dentro del tejido es fagocitada y usada como mitógeno por la célula de Schwann; en el caso del explante de ganglio sensorial, contando con el efecto mitogénico que ejercen las neuritas. Adicionalmente, la disociación de los tejidos permite la interacción de las células con substratos lo cual proporciona una adecuada superficie intercelular que estimula migración y proliferación.

Para los cultivos de explantes de nervio, se usaron modificaciones de las metodologías de Rutkowski et al. (28) y Askanas et al. (1), para nervios disociados las de Assoulin et al. (29) y Brokes et al. (30). Para los cultivos de explantes de ganglio, se modificaron las metodologías de Chi et al. (16) y de Salzer y Bunge (2) y para el ganglio disociado se utilizaron metodologías basadas en Manthorpe y Varón (31) y Gu et al. (32).

A continuación, se describen brevemente las metodologías.

Se extrajeron los nervios ciáticos y se liberaron del epineurio con la ayuda de pinzas de relojero y se cortaron en finos trozos de alrededor de 1 $\mathrm{mm}^{3}$. Estos explantes se colocaron sobre cajas de plástico o cubreobjetos de vidrio cubiertos o no con poli-L-lisina (Sigma) o colágeno (Sigma) y se sumergieron en medio completo (DMEM (Sigma)+SFB (Gibco) 10\% + antibióticos (Sigma) $100 \mathrm{U} / \mathrm{mL}$ penicilina $100 \mathrm{mg} / \mathrm{mL}$ estreptomicina) en un volumen que mantuviera húmedos los explantes sin sobrepasar su superficie, favoreciendo la adhesión y migración celular. En el caso de nervios disociados, se realizó una digestión enzimática con una mezcla de dispasa (Gibco)/colagenasa $(0,4 \mathrm{U} / \mathrm{mL}$ y 80 $\mathrm{U} / \mathrm{mL}$ ) en medio completo durante 3 horas a $37^{\circ} \mathrm{C}$. Se promovió la disgregación tisular por pipeteo. Finalmente, se lavaron la células tres veces con DMEM y se sembraron en medio completo+toxina colérica (Sigma) $0,1 \mu \mathrm{g} / \mathrm{mL}$ y forskolina (Sigma) $2 \mu \mathrm{M}$.

La obtención de los ganglios sensoriales (DRG) se realizó según la metodología descrita por Castellanos et al. (33). Los ganglios fueron cultivados igual que los explantes de nervio y los cultivos disociados se realizaron como se describe a continuación. Las células se obtuvieron por disociación de ganglios con colagenasa $280 \mathrm{U} / \mathrm{mL}$ por $1 \mathrm{~h}$ a $37^{\circ} \mathrm{C}$ y se resuspendieron en medio completo mas los mitógenos, toxina colérica $(0,1 \mu \mathrm{g} / \mathrm{mL})$ y forskolina $(2 \mu \mathrm{M})$. Las células se siembran en un frasco de cultivo de $25 \mathrm{~cm}^{2}$, previamente cubierto con una solución de colágeno tipo I $(10 \mathrm{mg} / \mathrm{mL})$. Este constituye el cultivo primario. El medio de cultivo se cambia 3 veces por semana hasta llegar a confluencia. Posteriormente, se realizaron otros dos pasajes (una vez se ha alcanzado confluencia) por tripsinización con una solución de $560 \mathrm{U} / \mathrm{ml}$ de tripsina (Sigma) preparada en DMEM.

La viabilidad celular se determinó en el momento de la siembra utilizando el método de exclusión del azul tripano (Sigma) (34) y a lo largo de los pasajes sobre células adheridas al cubreobjetos, contando bajo microscopio invertido con objetivo $10 \mathrm{X}$ durante 3,10 y 20 días de incubación a $37^{\circ} \mathrm{C}$ en medio completo. También se estimó la viabilidad por cuantificación de la absorbancia de la precipitación de la sal tetrazo- 
lium (MTT) (Sigma) a formazán por células adheridas (35). Estas absorbancias se extrapolan sobre una curva de calibración de número de células vs. absorbancia. Las cuantificaciones de viabilidad celular se realizaron en 3 ensayos.

\section{Cocultivos a largo plazo}

Cultivos enriquecidos en células de Schwann fueron cocultivados con neuronas sensoriales de DRG, según Kleitman et al. (36). Así, para la obtención de neuronas purificadas se utilizó como agente antimitótico citocina arabinósido (Sigma) que selecciona células que no están en división activa (neuronas) permitiendo eliminar un alto porcentaje de células en proliferación tales como los fibroblastos y las células de Schwann. Estos cocultivos se mantuvieron en medio completo más toxina colérica $0,1 \mu \mathrm{g} / \mathrm{mL}$, forskolina $2 \mu \mathrm{M}$ y ácido ascórbico (Sigma) $50 \mu \mathrm{g} /$ $\mathrm{mL}$.

\section{Estudios morfológicos}

Cultivos enriquecidos en células de Schwann, fueron sembrados en cajas de cultivo de $35 \mathrm{~mm}$ cubiertas con colágeno, lavados 3 veces con DMEM y fijados con glutaraldehído al $2 \%$ por 30 min. Posteriormente, fueron postfijados con tetróxido de osmio al 1\% durante una hora y deshidratados con etanol en concentraciones ascendentes de $70,80,90,95$ y $100 \%$ durante 10 min cada uno. A continuación se embebieron en resina epóxica EPON-812 en diluciones de $2: 1,1: 1$ y $1: 2$ con etanol al $100 \%$ durante 20 minutos. Finalmente, se incubaron durante una hora con resina EPON pura y se polimerizaron en nueva resina pura a $60^{\circ} \mathrm{C}$ durante 18 horas. Se efectuaron cortes semifinos y ultrafinos con un ultramicrótomo. Los cortes ultrafinos fueron contrastados con acetato de uranilo y citrato de plomo y observados bajo microscopio electrónico de transferencia, Philips 100.

\section{Resultados}

\section{Cultivo celular}

Tanto de explante de nervio ciático como de ganglio de raíz dorsal, se observó migración y proliferación de células de Schwann y fibroblastos, aunque con un alto nivel de proliferación de estos últimos. La foto 1 muestra un explante de nervio ciático con crecimiento y migración celular. La foto 2 muestra un explante de ganglio con algunos cuerpos neuronales y un gran halo de células.

Cuando se realizó disociación de nervio esperando tener células liberadas del tejido que migraran y proliferaran más activamente, se encontró que el tejido era difícilmente digerido aun usando agitación continua y diversas concentraciones de enzimas. Esto impidió la obtención de una suspensión homogénea con pérdida de gran cantidad de células atrapadas en los detritos y baja viabilidad por el largo período de digestión y acción enzimática. Así se recuperó un número pequeño de células de Schwann, por lo cual este sistema se descartó rápidamente.

Al digerir los ganglios sensoriales, se obtuvieron suspensiones homogéneas en un corto período de tiempo (foto 3) con una eficaz recuperación celular y con una preservación de la viabilidad de cerca de $90 \%$. Por todo lo anterior, se decidió utilizar como fuente de células de Schwann los ganglios disociados de raíz dorsal.

Se observó el enriquecimiento de los cultivos, luego de realizar tres pasajes. Inicialmente, en el cultivo primario se observaron cuerpos neuronales asociados con células de Schwann (células satélites) y otras migrando. Igualmente, los fibroblastos se encontraron migrando. Realizada la primera tripsinización, aproximadamente a los 7 días se observaron tanto células con morfología típica de Schwann (forma de huso, birrefringentes, núcleos alargados), como células de tipo fibroblasto poco refringentes, citoplasma extendido, núcleo grande y aplanado) (foto 4). Posterior a la segunda tripsinización, se evidenció un considerable aumento en células de Schwann (foto 5). Finalmente, se observó un alto enriquecimiento de los cultivos al tercer pasaje (foto 6). Así, los cultivos obtenidos con la metodología descrita presentaron características morfológicas que indican que están altamente enriquecidos en células de Schwann. Esto se evidenció por la presencia de 
gran cantidad de células fusiformes bastante refringentes, con prolongaciones largas y con núcleos pequeños y ovalados formando cadenas (fotos 6,10 ), que refleja su organización in vivo. Estos cultivos permanecieron estables con ausencia de transformación (evidenciada por la conservación morfológica), viables y enriquecidos hasta el quinto pasaje, aproximadamente por tres meses.

Respecto a la productividad, partiendo de la digestión de 40 ganglios extraidos de un animal, equivalentes a aproximadamente 200.000 células de Schwann en el cultivo primario y luego de tres pasajes de purificación bajo la acción de los mitógenos, se obtuvo una población de 3'600.000 \pm 470.000 (número de células \pm desviación estándar) de células de Schwann. Resultados similares se observaron en todos los cultivos realizados.

\section{Adhesión y viabilidad celular}

Respecto a los ensayos con diferentes substratos, observamos que independientemente de usar poli-L-lisina o colágeno se observó una adecuada adhesión y migración celular. Sin embargo, el sustrato de colágeno favoreció la migración, el alineamiento y la agrupación de las células en su disposición característica. Debido a esto, se eligió el colágeno como el sustrato más adecuado.

Los resultados de viabilidad en el momento de la siembra para cada pasaje (resultados de tres ensayos) se presentan en el cuadro 1.

Cuadro 1. Porcentaje de viabilidad con azul tripano en el momento de la siembra.

\begin{tabular}{lcccc}
\hline Tiempo & Inicial & Pasaje 1 & Pasaje 2 & Pasaje 3 \\
\hline $\begin{array}{l}\text { Viabilidad } \\
\% \pm D E\end{array}$ & $87,2 \pm 5,4$ & $88,1 \pm 2,6$ & $86,0 \pm 3,5$ & $84,5 \pm 4,4$ \\
\hline
\end{tabular}

DE: desviación estándar

Se realizó la cuantificación de los porcentajes de adhesión de las células de Schwann de tercer pasaje a diferentes tiempos de incubación con azul tripano y MTT. Se observaron los siguientes resultados (cuadro 2).
Cuadro 2. \% Porcentaje de células viables.

\begin{tabular}{|c|c|c|c|}
\hline & \multicolumn{3}{|c|}{ Días de adhesión } \\
\hline & $\begin{array}{c}3 \\
\% \pm D S\end{array}$ & $\begin{array}{c}10 \\
\% \pm D S\end{array}$ & $\begin{array}{c}20 \\
\% \pm D S\end{array}$ \\
\hline $\begin{array}{l}\text { Viabilidad (\%) } \\
\text { Azul tripano }\end{array}$ & $87,6 \pm 6,10$ & $84,0 \pm 2,30$ & $85,0 \pm 3,20$ \\
\hline Mtt & $80,0 \pm 0,02$ & $82,0 \pm 2,10$ & $84,5 \pm 0,16$ \\
\hline
\end{tabular}

DE: desviación estándar

Después de 20 días de adhesión, se concluyó que durante este tiempo de evolución no se alteró el porcentaje de adhesión de las células en el cultivo.

\section{Cocultivos a largo plazo}

Los cocultivos mantenidos durante un mes en las condiciones descritas, presentaron inicialmente emisión de neuritas a las que se asociaron claramente células de Schwann como lo muestra la foto 7. Estas células presentaron morfología típica de células de Schwann y proliferación activa. Se presentaron alineadas a lo largo de las neuritas. Posteriormente, a diferencia de su aspecto inicial refringente, fino y flotante, estas neuritas al asociarse estrechamente con el sustrato celular aumentaron su calibre y su aspecto de torno denso y compacto mostrando abundantes redes de neuritas (foto 8). Estas estructuras son semejantes a células de Schwann en proceso de mielinización, previamente informados en la literatura (36); sin embargo, hubo ausencia de coloración con el negro sudán, colorante específico para lípidos.

\section{Morfología}

Las células de Schwann en cultivo se observaron mononucleadas, con núcleo central elongado (foto 9). El citoplasma se observó rico en ribosomas y retículo endoplásmico liso y rugoso, mitocondrias y vesículas endocíticas (coat pit) junto con abundantes cuerpos osmiofílicos (foto 10). Se observó superposición de células adyacentes alineándose en su agrupación típica (foto 10).

\section{Discusión}

De acuerdo con observaciones en contraste de fase, se ha descrito ampliamente la célula de 

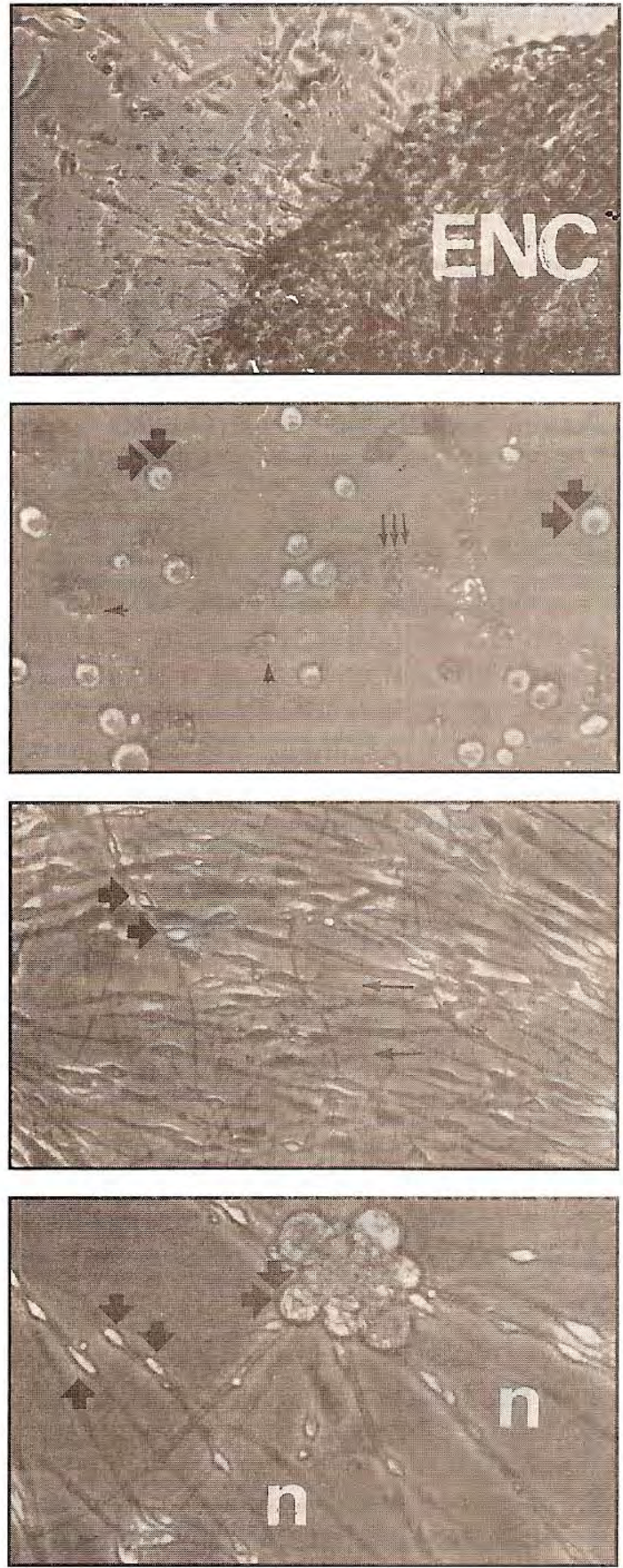
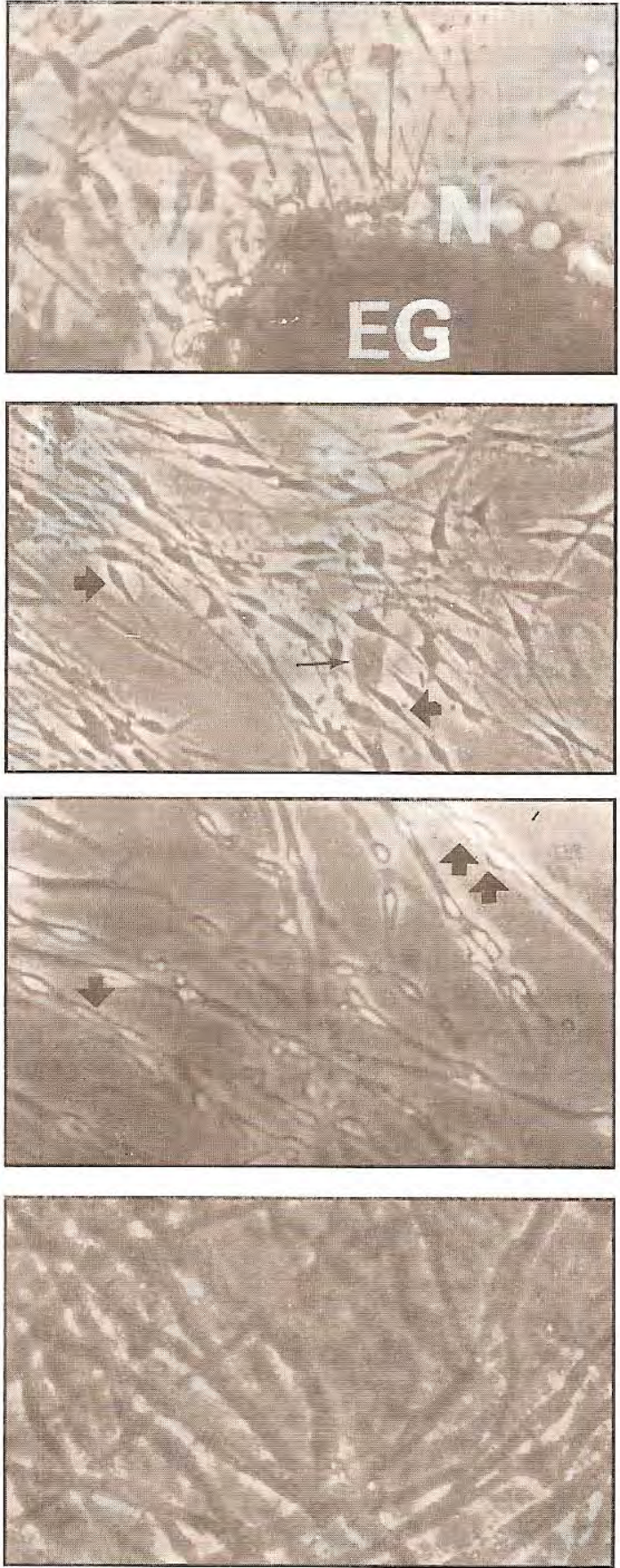

Figura 1. Foto 1: explante de nervio ciático (ENC); foto 2: explante de ganglio (EG) con cuerpos neuronales (N); foto 3 : cultivo primario; ganglio digerido con colagenasa. Se observan neuronas ( $M$; células no neuronales $(\downarrow w)$ y desechos de mielina ( $\downarrow$ ); foto 4: primer pasaje; ausencia de neuronas, presencia de células de Schwann (l) y fobroblasios ( $)$ ); foto 5: aumento del número de células de Schwann $(\$)$ e iniciación de su disposición en cadenas; foto 6: cultivo enriquecido con células de Schwann alineadas ( $(\mathbf{l})$; foto 7: cocultivo de neuronas sensoriales y células de Schwann; asociación de las neuritas al sustrato celular (n); foto 8: cocultivo a largo plazo con estructuras semejantes a células de Schwann en proceso de mielinización. Aumento 500X. 

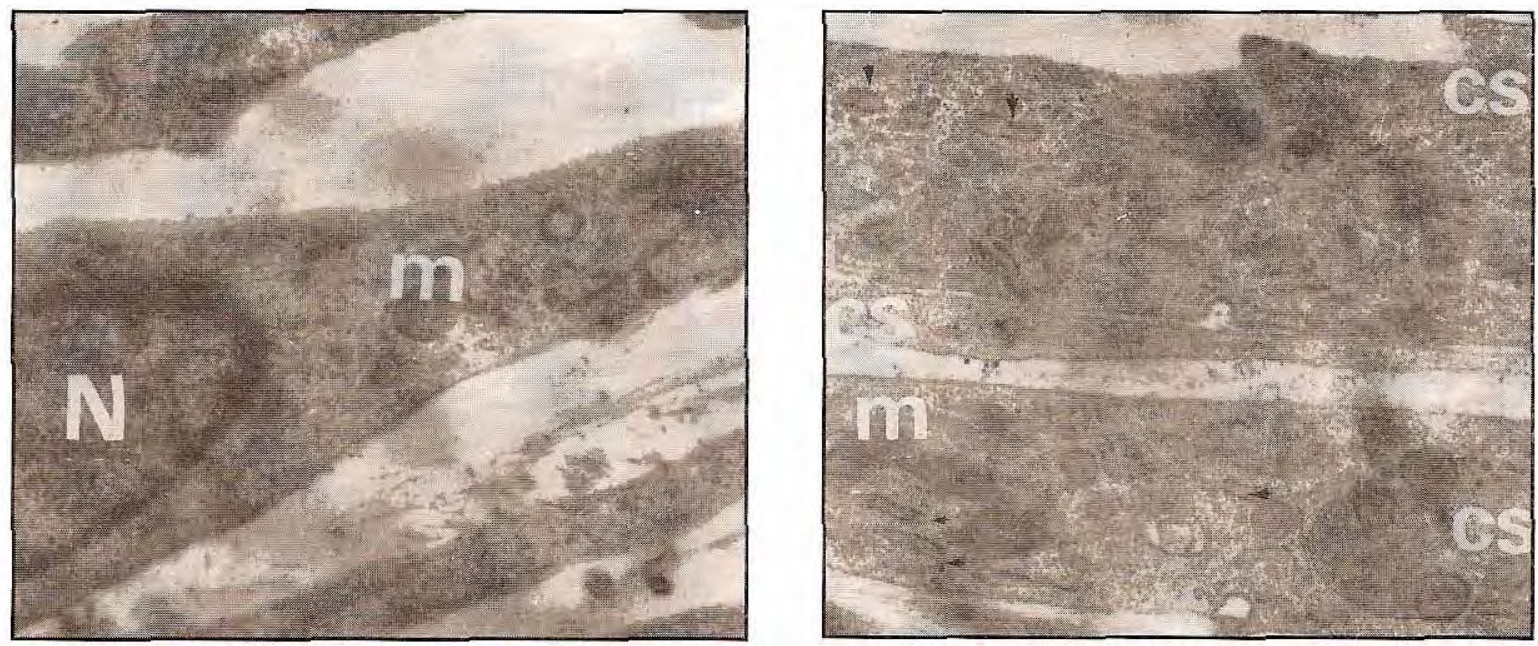

Figura 2. Foto 9: ultraestructura de la célula de Schwann; detalle del núcleo (N) y zona perinuclear. Se observa mitocondria $(\mathrm{m})$. Foto 10: ultraestructura de la célula de Schwann; detalle del citoplasma y alineación e interacción celular. Se observan tres células adyacentes, retículo endoplásmico rugoso $(v)$, mitocondrias $(\mathrm{m})$.

Schwann en cultivo, como una célula típicamente bipolar muy refringente, con su citoplasma relativamente compacto y con un núcleo denso y redondeado. Estas células, además, tienden a formar agrupaciones a manera de rosario traslapándose unas con otras; algunas adquieren una morfología tripolar, pero conservan el resto de características. A diferencia de éstas, los fibroblastos en cultivo poseen una morfología típica que presenta un núcleo grande poco denso con un citoplasma muy explayado sin refringencia, con un aspecto muy aplanado sobre el sustrato de cultivo $(1,8$, $37,38)$. Al igual que en informes previos, nuestra metodología permite obtener cultivos con las características descritas. De la misma forma, las observaciones ultraestructurales mencionadas son comparables con las informadas en la literatura (1).

Con base en nuestras observaciones, concluimos que el cultivo de células de Schwann de ratón adulto es más eficiente a partir de ganglios disociados que de las otras fuentes celulares estudiadas. Esto debido a tres factores principales: 1) el colágeno utilizado como sustrato favorece la supervivencia y adhesión celular por ser parte de la matriz extracelular (16), influye y favorece la agrupación en cuentas de collar, la morfología ahusada característica y tiene un efecto supresor sobre la proliferación de los fibroblastos (39), los cuales, por ser su tiempo de duplicación más rápido que el de las células de Schwann, tienden a sobrepoblar los cultivos; 2) el efecto mitogénico de las neuronas presentes en el cultivo primario y el alto número de células satélites que se derivan de ellas es mediado por el contacto axonal. Así, Salzer y Bunge (2) han informado valores de proliferación menores de $5 \%$ en ausencia de neuritas, mientras que, en presencia de éstas, los valores fueron cercanos a $90 \%$. De Vries (11) describió otros mitógenos que se restringen a los conos de crecimiento. De esta manera, neuronas y neuritas estimulan el enriquecimiento en los cultivos; 3) el uso de agentes activadores de la adenilato ciclasa y la elevación del AMP cíclico intracelular regulan la transcripción de genes involucrados en el ciclo celular. Como blancos han sido descritos elementos reguladores sensibles a AMP cíclico CRE- localizados en una región palindrómica de 8 pares de bases TG/TACGTCA y la región activadora de la proteína AP2, ambos optimizadores y aceleradores de la transcripción basal (12). La toxina colérica y forskolina a bajas concentraciones, permiten la 
forskolina a bajas concentraciones, permiten la activación de la adenilato ciclasa, a través de receptores gangliósido (GM1) y tirosina-cinasa (AX1 y RSE) (17), respectivamente, aumentando los niveles de AMPc que inducen la aparición de receptores a posibles mitógenos presentes en el suero. En condiciones normales en medio DMEM+SFB $10 \%$ inactivado, el tiempo de duplicación de las células es de 7 a 8 días. Cuando se adiciona TC, el número de células se incrementa rápidamente adquiriendo un tiempo de duplicación de 48 horas (10). La elevación de los niveles de AMPc imitan eventos en el desarrollo de células de Schwann que ocurren in vivo en E16 (13), tiempo en el cual la proliferación de células de Schwann está activa. Adicionalmente, este aumento de AMPc inhibe y retarda la proliferación de los fibroblastos no deseables. Igualmente, dichos activadores del CAMP a altas concentraciones pueden promover la expresión de genes relacionados con proteínas de la mielina y, en consecuencia, inducir la diferenciación. La aplicación de análogos de CAMP como el dibutiril CAMP o el 8-bromo AMP y la forskolina inducen la aparición de galactocerebrósido de superficie en las células de Schwann. Concentraciones 10 veces mayores que las usadas para producir proliferación inducen la expresión de gal $\mathrm{C}$ y otras moléculas de superficie así como glicoproteína asociada a la mielina (MAG) y la P0 requieren adicionalmente del contacto axonal (40). Sin embargo, en los cocultivos a largo plazo y usando concentraciones de mitógenos inductoras de proliferación, observamos estructuras semejantes a mielina. Estas estructuras serán objeto de estudios posteriores.

El modelo descrito permite obtener cultivos enriquecidos de células de Schwann de adulto que poseen características semejantes a éstas in vivo conservando la estabilidad en la viabilidad, la adhesión, la morfología y la ultraestructura, lo que las hace útiles para posteriores aplicaciones. Adicionalmente, cocultivos con neuronas obtenidas a partir de ganglios de raíz dorsal permiten estudiar in vitro eventos exclusivos del sistema nervioso como la mielinización, la interacción intercelular, la expresión de proteínas específicas, etc.

\section{Agradecimientos}

Este trabajo se realizó gracias al apoyo financiero del INS y de Colciencias (proyecto No. 2104-05-002-92). Agradecemos a la doctora Patricia Beltrán por su valiosa colaboración técnica en el desarrollo de este trabajo.

\section{Referencias}

1. Askanas V, Engel WK, Dalakas MC, Lawrence JV, Carter LS. Human Schwann cells in tissue culture. Histochemical and ultrastructural studies. Arch Neurol 1980;37:329.

2. Salzer JL, Bunger RP. Studies of Schwann cell proliferation. I. An analysis in tissue culture of proliferation during development, Wallerian degeneration, and direct injury. J Cell Biol 1980;84:739.

3. Griffin JW, Kidd G, Trapp BD. Interactions between axons and Schwann cells. In: Dick-Thomas, eds. Peripheral neurophaty. Third edition. W.B. Saunders, Vol. 1; 1993:317.

4. Webster H. Development of peripheral nerve fibers. In: Dick-Thomas, eds. Peripheral neurophaty. Third edition. W.B. Saunders, Vol. 1; 1993:243.

5. Ziller C, Le Douarin VM. The neural crest in nerve development. In: Dick-Thomas, eds. Peripheral neurophaty. Third edition. W.B. Saunders, Vol. 1; 1993: 237.

6. Gold R, Toykia KV, Hartung HP. Sinergic effect of INF- $\gamma$ and TNG- $\alpha$ on expression of immune molecules an antigen presentation by Schwann cells. Cel Immunol 1995;165:65.

7. Bunge MB, Bunge RP, Kleitman N. Role of the peripheral nerve extracelular matrix in Schwann cell function and in neurite regeneration. Dev Neurosci 1989;11:348.

8. Haynes LV, Rushton JA, Perrins MF, Dyer JK, Jones R, Howell R. Diploid and hyperdiploid rat Schwann cell strains displaying negative autoregula-tion of growth in vitro and myelin sheath-formation in vivo. J Neurosci Meth 1994;52:119.

9. De Deyne PG, De Vries GH, Bigbee JW. Camp-induced morphological changes in an immortalized Schwann cell line: a prelude to differentiation? Cell Motil Cytoskel 1994;29:20.

10. Raff M, Hornby-Smith A, Brockes JP. Cyclic AMP as mitogenic signal for cultured rat Schwann cell. Nature 1978;273(22):672. 
11. De Vries G. Schwann cell proliferation. In: Dick Thomas, Peripheral neurophaty, Vol. 1.; 1993:290.

12. Roesler WJ, Vandenbark GR, Hanson RW. Cyclic AMP and deinduction of eukaryotic gene transcription. J Biol Chem 1988;263(19):9063.

13. Morgan L, Jessen K, Mirsky R. The efeccts of CAMP on diferentiatión of cultured Schwann cells: progresion from a early phenotype (O4+) to a myelin phenotipe (Po+, GFAP-, N-CAM-, NGF-Receptor-) depends on growth inhibition. J Cell Biol 1991;112(3): 457.

14. Schumacher M, Jung-Testas I, Robel P, Baulieu EE. Insulin-like growth factor I: a mitogen for rat Schwann cells in the presense of elevated levels of cyclic AMP. Glia 1993;8:232.

15. Baron-Van Evercooren A, Leprince P, Rogister B, et al. Expression of plasminogen-activator activity predominates in the proliferating cell populations. Proc Natl Acd Sci USA 1984;81:7216.

16. Chi $\mathbf{H}$, Horie $\mathbf{H}$, Ikawa $\mathbf{N}$, Takinaka T. Isolation and age-related characterization of mouse Schwann cell from dorsal root ganglion explant in type I collagen gels. J Neurosci Res 1993;37:183.

17. Li RH, Chen J, Hammonds G, Philips $\mathbf{H}$, Armanini N, Wood P, Bunge R, Godowskil PJ, Sliwkowski MX, Anmather JP. Identification of Gas6 as a growth factor for human Schwann cells J Neurosci 1996; 16(6):2012.

18. Davis JB, Stroodoant P. Platelet-derived growth factors and fibroblast growth factor are mitogens for rat Schwann cells. J Cell Biol 1990;110:1353.

19. Wood PM, Bunge R. Evidence that sensory axons are mitogenic for Schwann cells. Nature 1975;256: 662.

20. Ridley D, Jopling W. Classification of leprosy according to immunity. A five group system. Int J Lepr 1966; 34:255.

21. Zhang QL, Lin PX, Chang $\mathbf{Y}$, Webster $\mathbf{H}$. Effects of nerve segment supernatants on cultured Schwann cell proliferation and laminin production. J Neuro Res 1994;37:612.

22. Sobue G, Brown J, Kim So, Pleasure A. Axolemma is a mitogen for human Schwann cells. Ann Neurol $1984 ; 15(5): 449$.

23. Ratner N, Hong D, Licberman MA, Bunge RP, Glaser L. The neuronal cell-surface molecule mitogenic for Schwann cells is a heparin-binding protein. Proc Natl Acad Sci USA 1988;85:6992.

24. Morrissey TK, Levil ADO, Nuijens A, Sliwkowski M, Bunge RP. Axon-induced mitogenesis of human
Schwann cells involves heregulin and p185 ${ }^{\mathrm{erb} \beta 2}$. Proc Natl Acad Sci USA 1995;92:1431.

25. Kalderon N. Schwann cell proliferation an localized proteolysis expression of plasminogen-activator activity predominates in the proliferating cell populations. Proc Natl Acad Sci USA 1984;81:7216.

26. Soboue G, Pleasure D. Schwann cell galactocerebroside induced by derivatides of adenosine $3^{\prime}, 5^{\prime}$, monophosphate. Science 1984;224:72.

27. Davey DF, Ansselin AD, Corbeil SD. Culture of Schwann celis from adult animal in vitro. Cell Dev Biol 1995;31:253.

28. Rutkowski JL, Tennekoon GI, McGillicuddy GE. Selective culture of mitotically active human Schwann cell from adult surai nerve. Ann Neurol 1992;31:580.

29. Assouline JG, Bosch EP, Lim R. Purification of rat Schwann cells from cultures of peripheral nerve. In: A dissection and tissue culture. Manual of the nervous system. RA Liss; 1989:247-250.

30. Brockes JP, Fields KL, Raff MC. Studies on cultured rat Schwann cells. I. Establishment of purified populations from cultures of peripheral nerve. Brain Res 1979;165:105.

31. Manthorpe M, Varon S. Purification of neonatal mouse dorsal root ganglion Schwann cells. In: A dissection and tissue culture. Manual of the nervous system. Alan R. Liss, Inc.; 1989:243-6.

32. Gu X, Thomas PK, King RHM. Chemotropism in nerve regeneration studied in tissue culture. J Anat 1995; 186:153.

33. Castellanos JE, Castañeda DR, Velandia AE, Hurtado H. Partial inhibition of the in vitro infection of adult mouse dorsal root ganglion neurons by rabies virus using nicotinic agonists. Neuroscience Letter 1997;229:1.

34. Freshney RI. Culture of animal cell: a manual of basic techniques. New York: Alan R. Liss; 1988: chapter 18.

35. Denizo TF, Lang R. Rapid colorimetric assay for cell growth and survival. Modifications to the tetrazolium dye procedure giving improved sensitibity and releability. $J$ Immunol Meth 1986;89:271.

36. Kleitman N, Wood PM, Bunge R. Tissue culture methods for the study of myelination. Culturing nerve cells. Acton: William K. Bradford Publishing Co.;1991: 337.

37. Morrissey TK, Kleitman N, Bunge RP. Isolation and functional characterization of Schwann cells derived from adult peripheral nerve. J Neurosci 1991;11:2433.

38. Scarpini E, Baron P, Scarlato G. Human Schwann cells in culture. Recent advances to nerve pathology. In: Gorio A, editor. Neuroregeneration. New York: Raven Press Ltd.; 1993. 
39. Kono T, Tanii T, Furukawa M, Mizuno N, Kitajima J, Ishii M, Hamada T, Yoshizato K. Parallel arrangement growth inhibition and cell cycle phace analysis of human dermal fibroblast cultured in colagen lattice. J Dermatol 1990;17:2.
40. Soboue G, Shuman S, Pleasure D. Schwann cell responses to ciclic AMP: proliferation, change in shape and appearance of surface galactocerebro-side. Brain Res 1986;362:23. 